EDITORIAL

A tribute to the scientific career of Neville Greaves: the Daresbury years

To cite this article: Alan V Chadwick and C Richard A Catlow 2021 J. Phys.: Condens. Matter 33320401

View the article online for updates and enhancements.

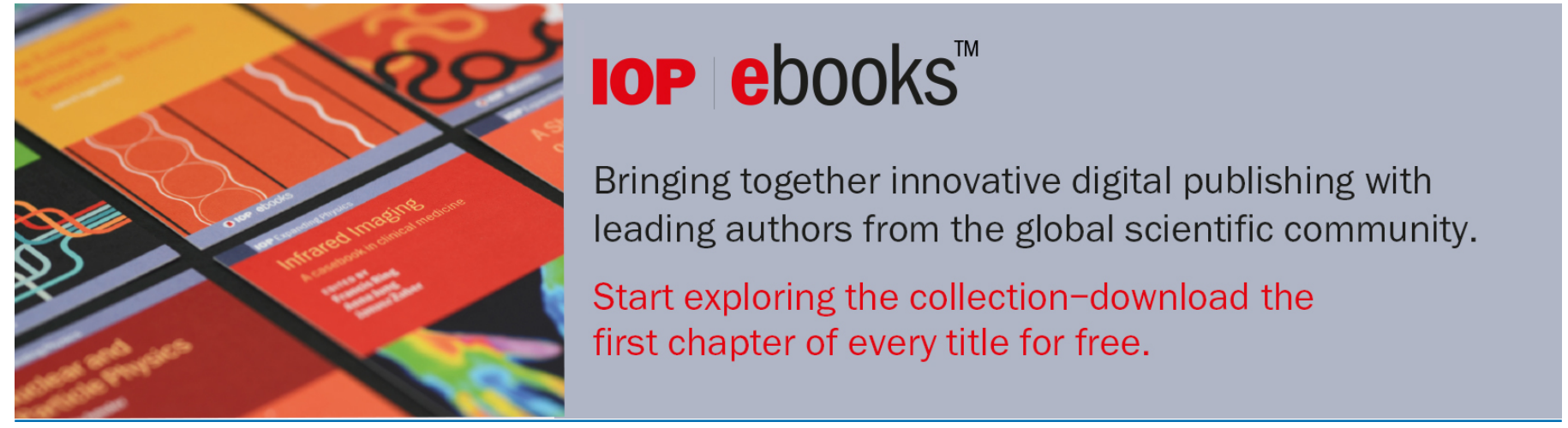

This content was downloaded from IP address 144.82 .114 .253 on $04 / 08 / 2021$ at $12: 57$ 


\title{
A tribute to the scientific career of Neville Greaves: the Daresbury years
}

\author{
Alan V Chadwick ${ }^{1, *}$ (1) and C Richard A Catlow ${ }^{2,3}$ \\ 1 School of Physical Sciences, University of Kent, Canterbury, Kent CT2 7NH, United Kingdom \\ 2 Department of Chemistry, University College London, 20 Gordon St., London WC1 HOAJ, United \\ Kingdom \\ ${ }^{3}$ School of Chemistry, Cardiff University, Park Place, Cardiff CF10 1AT, United Kingdom \\ E-mail: a.v.chadwick@kent.ac.uk and c.r.a.catlow@ucl.ac.uk
}

Received 1 March 2021, revised 22 March 2021

Accepted for publication 19 May 2021

Published 18 June 2021

\begin{abstract}
We present a personal account of both the developments in technique and instrumentation led by Neville Greaves and the scientific applications which they enabled. We focus on the pioneering period at the Synchrotron Radiation Source, Daresbury in the 1980s and 90s. We discuss and illustrate the lasting impact of these key developments on chemistry, materials and catalytic science
\end{abstract}

Keywords: synchrotron radiation, XAS, EXAFS, XANES, SAXS/WAXS

(Some figures may appear in colour only in the online journal)

\section{Introduction}

Neville Greaves' research interests were very wide and as the articles in this issue testify he made significant contributions in several areas of science. In this personal and informal review, we will examine the contributions that he made during his period of work at the Daresbury Synchrotron Radiation Source (SRS) between 1976 and 1996, the period of our closest research collaborations, which will cover both his substantial contributions to instrumentation and techniques as well as to a diverse range of applications in chemical and physical sciences.

Before we concentrate on the specific areas of Neville's work we will outline the origins of our collaboration as it shows that the strongest links occur by chance and are rarely engineered. In 1979 one of us (AVC) attended the winter Gordon conference on orientationally disordered solids in Santa Barbara. Also at the meeting was John Sherwood from Strathclyde, with whom AVC had spent two very fruitful years as a PDRA. John had decided we should drive up the coast to San Francisco visiting the usual tourist spots. At the end of the trip John arranged that we should visit SPEAR, the Stanford

\footnotetext{
* Author to whom any correspondence should be addressed.
}

synchrotron, as he was interested in x-ray topography and was planning experiments at the newly commissioned SRS. AVC went on the visit and was given lots of booklets on SPEAR and on the transatlantic flight home read some and was interested in a list of the funded projects as it included one from Art Nowick at Columbia on the study defective ionic solids by EXAFS. This was intriguing as Art was a doyen of ionic crystal research and if he was using EXAFS it suggested it must be important. A coffee time chat back at Kent with John Dore (a physicist) gave some insight but more importantly he suggested I should talk to Neville Greaves at Daresbury. After a few phone calls a meeting was arranged at the SRS. The present authors were already collaborating on defects in alkaline earth fluorites, a very hot topic at that time as they are a model for $\mathrm{UO}_{2}$ and of major interest to scientists at UKAEA Harwell. Hence a very productive and memorable day was spent with Neville at the SRS. The three of us naturally gelled and we sketched out a proposal to the SERC for EXAFS studies of fluorites. The proposal was funded and we appointed an outstanding PDRA in Lee Moroney. One memory of the day was that in the Wire Wheels taxi back to Runcorn station we were so engrossed in discussing the research possibilities that we were half way to Liverpool before we realised the driver was lost. When we finally got to the station we had missed the train and had to wait an hour for the next one. 
That day was the start of a lifetime's collaboration and friendship. Neville had graduated with a BSc in Physics from St Andrews in 1968, went on to work as a research physicist with Pilkington UK R \& D labs followed by a PhD in Physics at Cambridge Cavendish Laboratory. By 1976, after a brief return to Pilkington his taste for academic research fostered at Cambridge which brought him to Daresbury in 1978. The collaboration worked well as each contributed a special expertise. Neville had a background in physics, an interest in materials (especially glass) and a deep knowledge of synchrotron techniques; CRAC's expertise was in computational modelling but also with experience with neutron scattering techniques; AVC was an experimental solid state chemist who grew the crystals for the early experiments and measured atomic defect structures and transport. The friendships were cemented by parties at the Seneschal's house, Neville's listed building house in Halton. In addition Neville's children were of similar age to those of AVC, and there is a memory of an anxious day at a conference in Munster in 1992 where we awaited the A-level results of our children. An outcome was that Neville's daughter Lucinda came to study at Kent and this led to a number of memorable family evenings together.

In hindsight the UK research councils funding of the SRS, the world's first dedicated SRS designed as a user facility, was very farsighted. Also, looking back it was a bold decision given that it was a period when the UK economy was in a poor state, typified by the introduction of the 'three day week' to save power, numerous strikes and very high inflation. When construction commenced in 1975, many of the synchrotron techniques were in their infancy and still to be fully proven. In fact the original case for building the SRS did not envisage many of the areas of later growth. However, the SRS proved to be an outstanding success $[1,2]$ in a wide range of disciplines and served many communities for almost three decades. One of these was that of materials science which Neville firmly established into the portfolio of the SRS. As we will show in the following sections he was responsible for the development of synchrotron techniques, including both the equipment and procedures, that progressed the understanding of a wide range of materials types, from catalysts to ceramics to glass.

\section{Science at the SRS}

\subsection{X-ray absorption spectroscopy}

X-ray absorption spectroscopy (XAS), the general term used to cover extended $\mathrm{x}$-ray absorption fine structure (EXAFS) and $\mathrm{X}$-ray absorption near edge structure (XANES), was one of the very novel techniques that was established as a crucial structural method from the very beginning of the SRS. The technique was only recently established by the pioneering papers of Stern, Lytle and Sayers between 1971 and 1975 [3-5] and the refinement of the theoretical basis by Lee and Pendry in 1975 [6]. At the SRS, the XAS measurements were roughly divided into two categories: biological and materials systems, the former under the supervision of Samar Hasnain [1] and the latter by Neville Greaves. The first publication from the SRS was an XAS study by Neville and co-workers [7] and the SRS

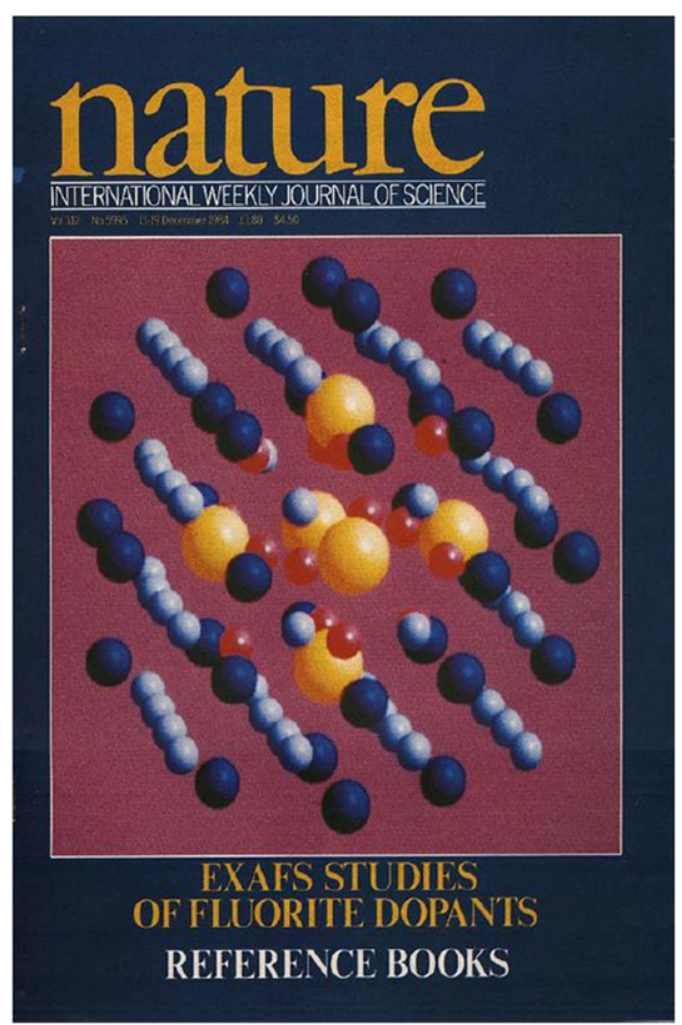

Figure 1. The front cover of Nature. Reprinted by permission from Springer Nature Customer Service Centre GmbH: Nature [8] (1985).

became particularly strong in XAS studies. It is noteworthy that when the SRS finally closed in 2007, Europe lost $25 \%$ of beam time available for XAS measurements. As a result the UK XAS community was badly affected by the 'dark period' (the time between the closing of the SRS and the opening of Diamond Light Source).

2.1.1. Conventional stations. At the SRS the experimental set-ups were referred to as stations, which were under the guidance of station masters, whereas at the Diamond Light Source the equivalent terms are beamlines and beamline scientist. The stations at the SRS were given numbers, $X . Y, X$ being the number of the line of beam and $Y$ the number of station on that line. The main XAS stations were 3.4, 7.1, 8.1, 9.2, 9.3 and 16.5, offering a wide energy range and diverse ancillary techniques.

Our collaboration with Neville began with investigations of the defect structures of fluorite structured materials using stations 7.1 and 9.2. These were conventional stations as the set-ups were fairly standard for that time i.e. a double crystal monochromator that rotated in millidegree steps, gas-filled ion chamber detectors, and a basic computer control arrangement. The current authors had been studying fluorites for some years, AVC growing the crystals and measuring the electrical properties and CRAC using neutron measurements and computer modelling. The inclusion of XAS measurements proved a vital step in revealing the defect structures of rare-earth doped calcium fluoride, to the extent that it made the front cover of Nature [8], see figure 1. 


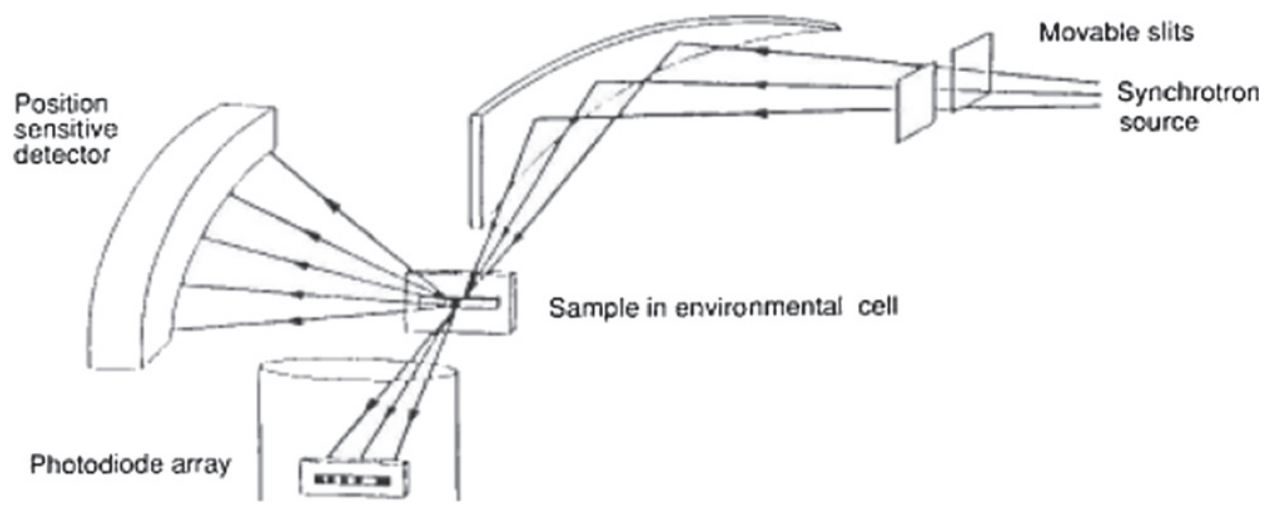

Figure 2. The components of the combined station on station 7.4. Reprinted by permission from Springer Nature Customer Service Centre GmbH: Nature [16] (1991).

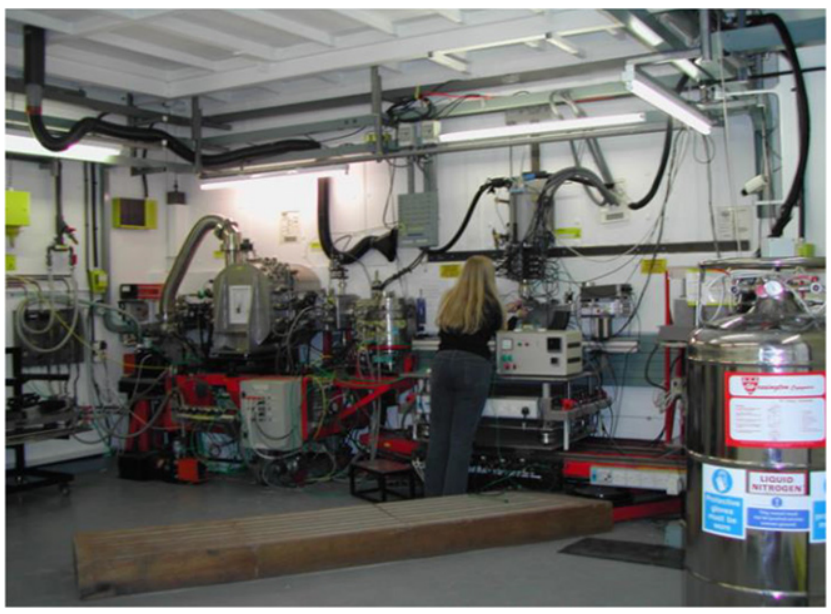

Figure 3. The experimental hutch on station 9.3 .

The work on calcium fluoride is well-documented elsewhere and the only additional comment was that it was saddening for a crystal grower to watch while gem-like, often brightly coloured crystals, were ground to fine powders for XAS samples. However, it was the study of an analogous system, yttrium doped zirconium dioxide (referred to as cubic zirconia, YSZ, and an important fuel cell membrane) that proved to be an experimental challenge.

We decided to measure the XAS for the Y and Zr K edges of YSZ as a function of temperature on station 9.2. The furnace used was designed by Lytle, very bulky and nearly $2 \mathrm{~m}$ in height as it included a power supply and water-cooling system. Unfortunately, the furnace was on station 7.1 and moving to 9.2 meant finding a route which avoided low pipes and obstacles. It took several hours of pouring over the plans of the SRS to define a suitable route and just as long to move the furnace. Our results were highly controversial [9] as we assigned the compensating oxygen vacancy as nearest neighbour to the $\mathrm{Zr}^{4+}$ ion. Other studies claimed the compensating oxygen vacancy was nearest neighbour to the $\mathrm{Y}^{3+}$ ion on the grounds of effective charge. We were proved correct and the debate was put to bed by a very thorough XAS study of zirco- nium oxides be Penner-Hahn and co-workers [10-12] which included measurements at $10 \mathrm{~K}$ to reduce thermal vibrations.

Although our collaboration began with a grant to study fluorites our first publication was an XAS study of polymer electrolytes [13]. At the time these systems were emerging as solid electrolyte membranes for lithium ion batteries and consisted of lithium salts dissolved in high molecular weight polyethylene oxide $[14,15]$. We studied the Rb K edge in the rubidium analogue which gave an insight into the cation environments.

2.1.2. Innovative stations. At the SRS Neville always wanted to explore the use of new methods and techniques and, together with Gareth Derbyshire and Andy Dent, he pioneered the development of stations that could combine XAS with other structural probes. The development was advanced in the early 1990s with a very fruitful collaboration with Sir John Meurig Thomas and his catalysis group at the Royal Institution. The first output from the collaboration was an in situ study of the $\mathrm{Cu} \mathrm{K}$ edge XAS as aurichalcite was converted to a catalyst for the methanol synthesis and water shift reaction [16]. The measurements were performed on station 7.4 and the experimental arrangement is shown schematically in figure 2. The arrangement allowed both the XAS and diffraction pattern to be collected on the same sample in a temperature controlled cell-a novel approach that could monitor long range and local structural changes during chemical reactions in a single shot rather than a lengthy scan with a stepping monochromator. The setup became a standard for time-resolved work, termed energy dispersive EXAFS (EDE) where position sensitive detector collects spectra in short time scales, down to milliseconds. Station 7.4 continued in this role until the closure of the SRS and beamline I.20-EDE at Diamond uses this arrangement and is a key tool in studies of catalysis.

A second innovation by Neville and the RI team was the development of station 9.3 [17]. This station was also capable of combining XAS with diffraction measurements and was equipped with a fluorescence detector and a sample cell capable of heating to $1000{ }^{\circ} \mathrm{C}$. It was also possible to collect quick EXAFS (QuEXAFS, scans taking the order of seconds), which will expanded in later sections. Another feature of 9.3 was a very large experimental hutch, as seen in figure 3 , which 




Figure 4. The glancing angle set-up on SRS station 9.2. Reprinted figure with permission from [22], Copyright (1992) by the American Physical Society.

allowed groups to bring in a wide range of ancillary equipment such as IR and UV spectrometers, mass spectrometers, gas rigs, etc. This was of major importance in more chemical applications and the station was heavily used by catalysis researchers up to the closure of the SRS. The equivalent at Diamond is the Core XAS beamline B18 on which there is high demand for beam time.

\subsection{Novel instrumentation}

2.2.1. Monochromators. An early problem that was recognised in transmission XAS experiments was that the beam contained components from higher harmonics of the fundamental reflection from the conventional double crystal monochromator. This meant that the measured absorbance was not correct as the harmonics would pass through the sample without being absorbed. This was overcome at the SRS by the use of an order sorting monochromator developed by Mike Hart and installed by Neville on station 7.1 [18]. The underlying physics was simple and very cleverly applied. The energy spread of the higher harmonics in the beam is much smaller than that of the fundamental reflection. Hence, moving the energy off the position of the maximum intensity of the reflected beam would reduce the contamination from the harmonics. This can be achieved by tipping one of the monochromator crystals with respect to the other one. We were involved in testing the order sorting monochromator early in our collaboration. One of the crystals was fitted with a solenoid/leaf-spring mechanism. The operating procedure involved finding the maximum exit beam intensities at the start and end energies of the proposed XAS scan by moving the crystal over the rocking curve. These values were input to a programme on the control computer; a linear change was assumed between the start and end energies and a feedback loop moved the crystal to a desired fraction of the maxima at each point in the scan. It was typical to use ' $50 \%$ harmonic rejection', which maintained the exit beam intensity to a half of the extrapolated maxima throughout the scan. This approach worked well except on multiple scans the drop off of the beam with time at the SRS meant the harmonic rejection was not operating properly after several scans and the rocking curve had to re-scanned. In systems where the beam is more stable, as it is at Diamond, the harmonic rejection is by mirrors in the beam line optics rather than adjustments in the monochromator mirrors.

A real breakthrough was the development, referred to above, of the quick scanning EXAFS (QuEXAFS) monochromator by Barry Dobson and first utilised by Samar Hasnain's group at the SRS [19]. It was Neville who recognised the potential in materials studies of combining it with XRD measurements [17, 20]. This monochromator moves at a fixed speed and the detector counts are collected 'on the fly' at prefixed time intervals. Thus a typical XAS scan can be collected in 10 to $300 \mathrm{~s}$, compared to the $30 \mathrm{~min}$ required with a stepping motor monochromator using alternate count, move and settle sequences. Thus the time of a QuEXAFS scan is commensurate with the time to collect an XRD pattern and the combination of the two on 9.3 of the SRS proved a real asset to materials groups. QuEXAFS is in standard operation on the Core XAS beamline B18 at Diamond which enables a very rapid turnover of samples, the order of 50 per day. There were numerous combined studies on 9.3 and our study of the growth during heating of iron and copper doped tin oxide nanocrystals is a typical example [21], especially as it was published in an issue celebrating the 65th birthday of Sir John Meurig Thomas. By monitoring the XAS of the dopant and the particle size from the XRD peak width, we showed the dopants moved to the surface as the particles grew. QuEXAFS is in standard operation on the Core XAS beamline B18 at Diamond which enables a very rapid turnover of samples, the order of 50 per day (figure 4).

2.2.2. Glancing angle XAS. Although we never used this during our collaboration with Neville he was a great advocate of this instrumentation to study materials [22]. The principle is that the below a critical angle the incident $\mathrm{x}$-ray beam will create photoelectrons only in the near surface region, a few $\mathrm{nm}$ deep, which will be seen in the associated fluorescence $\mathrm{x}$ rays. The measurement requires fitting a goniometer stage to hold the sample, which due to the large footprint of the beam, has to be large and very flat. A typical example is the study of dopants in the surface regions of amorphous silicon [22]. The samples were thin films deposited on glass and the dimensions 
were $25 \times 70 \mathrm{~mm}$ and had a warp of less than 5 microns along the length. For materials that can provide relatively large and extremely flat this technique is a very sensitive probe of the surface, a region which, of course controls many chemical and physical phenomena.

2.2.3. Detectors. Detector systems are key to most synchrotron experiments and include a sensitive element to capture the signal and the associated electronics to collect the large amounts of data that are generated in very short time periods. As leader of the materials section at the SRS Neville established a strong detector group in the late 1980s and they worked along side scientists and engineers. The SRS detector group included Gareth Derbyshire and Richard Farrow and they worked closely with Neville on several challenging projects. There were several detector developments at the SRS [2] and many were driven by Neville's interest in experiments that involved combined techniques and samples under dynamic conditions. He always encouraged the detector team to get a system that worked for the users and leave refinements to a later stage. The EDE experiments, described earlier, are a good example of the new demands on detectors. A VME-based control and data acquisition system was constructed [23] with performance characteristics of a $2 \mathrm{~ms}$ readout time for one scan of 512 pixels, at 16 bits resolution. Accumulation of 65000 scans in a single frame and a total of 64 frames stored in memory. A little later the XPRESS system was developed [24] to increase the throughput from multielement fluorescence XAS detectors by an order of magnitude per channel. A legacy of the SRS is the continued interest in detector development at Diamond.

\subsection{SAXS/WAXS}

The SRS was renowned for its success in SAXS/WAXS experiments on a beamline funded by the Dutch Research Council (ZWO), particularly in the field of polymer processing and characterisation with the initial work of Wim Bras and Tony Ryan. However, as confirmed by Wim, the development of the SAXS/WAXS technique was partially initiated and certainly made possible by Neville [25] even though there was initially little help from the less material science and more biology oriented Daresbury management. Neville supported the technique throughout his time at the SRS. He wished to use it for glass crystallization with Menno Oversluizen and provided the required INEL WAXS detector and the help of Gareth Derbyshire to install this detector. A somewhat clandestine effort of Geoffrey Mant in writing the data acquisition code provided the last required building block. In fact it became the first dedicated SAXS/WAXS station and had a large impact on not only materials science [26] but even on such diverse areas as skin/eczema research [27] and starch gelatinization [28]. The glass work was the initial driving force but the availability of the measurements enabled Tony Ryan to do very interesting work on polymers and these developments established a basis which kept the UK for many years in the forefront of synchrotron based polymer work [29]. After this development only very few SAXS only stations were built for materials work at synchrotrons.

\subsection{Diffraction}

The 1980s and 90s was also an exciting period for the development of the diffraction facilities at Daresbury; and a very thorough account of synchrotron based diffraction work at the SRS has been published by Bob Cernik [30]. The construction of X-ray diffraction (XRD) facilities began in the early 1980s and the chair of the powder diffraction project was one of the current authors (CRAC). The SRS diffraction programme grew over the years from a relatively basic powder diffraction system (station 9.1, [31]) to a suite of advanced stations including station 9.8 [32] for the single crystal studies of microand imperfect crystals and stations for combined techniques. Neville strongly supported the diffraction work and ensured the relevant stations were well-equipped, which included the purchase of the INEL position sensitive detector that found use on several stations. However, Neville would never have claimed to be a crystallographer; his interest was to combine XRD with other techniques to provide a deeper understanding of materials.

\section{Concluding remarks}

We realise that we have only touched on one aspect of Neville's contributions to science, namely his experimental work at the SRS. Nevertheless, that is a significant contribution as almost every UK user of XAS for the investigation of materials can trace their training back to Neville. From 1994-6 Neville was the UK member on the International Advisory Committee for the world's then largest SRS Spring 8 in Japan. We have not mentioned his life long study of glass structure and phases changes for which he published several seminal papers [33-37] and his work on Poisson's ratio which will soon be a citations classic ( $>1000$ citations) [38]. Similarly, we have left out his work in arranging several very successful conferences, some of which were particularly novel in that he tried to bring together communities with different interests. Among the conferences Neville organised was the 1994 'First European Conference on Synchrotron Radiation in Materials Science' held in Chester July 3-8. This was the first in a very successful series of meetings. Two of the eminent speakers were Sir John Meurig Thomas and Nobel Laureate Sir Neville Mott, both good colleagues with whom Neville had many phone calls and written correspondence over the years. We especially remember a three-day symposium entitled 'Science and Art in Glass', October 19-21, 1992, at the Royal Institution. A plenary speaker was Sir Alistair Pilkington who reviewed the float-glass project. This symposium was before its time in how it had succeeded in bringing together artists (like Dale Chihuly, whose sculptures can allegedly cost millions of dollars), architects, scientists, a curator and an antique specialist. The conference trips were evening tours of art galleries and the Victoria and Albert museum. The lectures were held in the iconic Faraday Lecture theatre at the Royal Institution and really succeeded in marrying artistic and scientific cultures.

Our final comments concern two examples of characteristics of Neville which we are sure his other collaborators will have witnessed, namely his dogged determination with experiments and his perfectionism in writing papers. It was on one of 
our very early visits to the SRS, a wet Saturday with a skeleton staff, that Neville decided to change the monochromator crystals on station 7.1. At that time the control computer did not retain any settings, particularly the angle of the monochromator crystals. The procedure was to set the crystals to the horizontal position and feed in that setting. So Neville went off to find a spirit level, but after 30 min he came back without one. He then proceeded to relate to us the properties of the human eye as a very accurate scientific instrument. He then went off to find a metre rule, again to no avail. But he came back with three one-foot rulers and a role of sellotape. After taping the rulers together to make roughly $1 \mathrm{~m}$ he then placed it on the monochromator crystals. We moved the angle of the crystals until Neville was satisfied it was horizontal and the control computer was set to zero. To our surprize when we did a scan of a copper foil the edge position was an only a few tenths of a degree out of alignment and we could carry on with the experiments. We would have given up and gone for a drink but Neville was determined that we would finish the experiments we had planned.

The writing of the Nature paper [8] brought out Neville's instinctive aim at perfection. We were going over a draft, about the sixth version, and Neville was insisting on making more corrections. At this point CRAC insisted we must finish it and have a final draft. Neville was unperturbed and told us that Franz Schubert had several attempts at writing his Great $\mathrm{C}$ Major symphony. CRAC's quick response was to remind us that Schubert also had an unfinished symphony and that would not happen to this paper. That amusing repartee broke the deadlock and the paper was finished in a few hours and that version sent to the journal.

\section{Acknowledgments}

Several of Neville's former colleagues and friends helped in the writing of this contribution. We are particularly grateful to Mrs Jennifer Greaves, Andy Dent, Gareth Derbyshire, Wim Bras, Barry Dobson and Bob Cernik.

\section{Data availability statement}

No new data were created or analysed in this study.

\section{ORCID iDs}

Alan V Chadwick (D) https://orcid.org/0000-0002-6485-9207

\section{References}

[1] Hasnain S S and Catlow C R A 2019 Phil. Trans. R. Soc. A 377 20190147

[2] Greaves G N, Catlow C R A, Derbyshire G E, McMahon M I, Nelmes R J and van der Laan G 2008 Nat. Mater. 7827

[3] Sayers D E, Stern E A and Lytle F W 1971 Phys. Rev. Lett. 27 1204

[4] Lytle F W, Sayers D E and Stern E A 1975 Phys. Rev. B 114825

[5] Stern E A, Sayers D E and Lytle F W 1975 Phys. Rev. B 114836

[6] Lee P A and Pendry J B 1975 Phys. Rev. B 112795
[7] Greaves G N, Durham P J, Diakun G and Quinn P 1981 Nature 294139

[8] Catlow C R A, Chadwick A V, Greaves G N and Moroney L M 1985 Nature 312601

[9] Catlow C R A, Chadwick A V, Greaves G N and Moroney L M 1986 J. Am. Ceram. Soc. 69272

[10] Li P, Chen I-W and Penner-Hahn J E 1993 Phys. Rev. B 48 10063

[11] Li P, Chen I-W and Penner-Hahn J E 1993 Phys. Rev. B 48 10074

[12] Li P, Chen I-W and Penner-Hahn J E 1993 Phys. Rev. B 48 10082

[13] Catlow C R A, Chadwick A V, Greaves G N, Moroney L M and Worboys M R 1983 Solid State Ion. 9-10 1107

[14] Armand M 1983 Solid State Ion. 9-10 735

[15] Xue Z, He D and Xie X 2015 J. Mater. Chem. A 3 19218

[16] Couves J W, Thomas J M, Waller D, Jones R H, Dent A J, Derbyshire G E and Greaves G N 1991 Nature 354 465

[17] Sankar G, Wright P A, Natarajan S, Thomas J M, Greaves G N, Dent A J, Dobson B R, Ramsdale C A and Jones R H 1993 J. Phys. Chem. 979550

[18] Greaves G N, Diakun G P, Quinn P D, Hart M and Siddons D P 1983 Nucl. Instrum. Methods Phys. Res. 208 335

[19] Dobson B R, Hasnain S S, Neu M, Ramsdale C A and Murphy L M 1993 Japan. J. Appl. Phys. 32192

[20] Murphy L M, Dobson B R, Neu M, Ramsdale C A, Strange R W and Hasnain S S 1995 J. Synchrotron Radiat. 264

[21] Davis S R, Chadwick A V and Wright J D 1997 J. Phys. Chem. B 1019901

[22] Greaves G N, Dent A J, Dobson B R, Kalbitzer S, Pizzini S and Müller G 1992 Phys. Rev. B 45617

[23] Derbyshire G E, Bogg D, Dent A J, Farrow R C, Greaves G N, Helsby W I, Morrell C, Ramsdale C A and Wells M P 1992 Rev. Sci. Instrum. 63790

[24] Farrow R, Derbyshire G E, Dobson B R, Dent A J, Bogg D, Headspith J, Lawton R, Martini M and Buxton K 1995 Nucl. Instrum. Methods Phys. Res. B 97567

[25] Bras W, Derbyshire G E, Ryan A J, Mant G R, Felton A, Lewis R A, Hall C J and Greaves G N 1993 Nucl. Instrum. Methods Phys. Res. A 326587

[26] Khandpur A K, Forster S, Bates F S, Hamley I W, Ryan A J, Bras W, Almdal K and Mortensen K 1995 Macromolecules 28879

[27] Bouwstra J A, Gooris G S, van der Spek J A and Bras W 1991 J. Invest. Dermatol. 971005

[28] Jenkins P J, Comerson R E, Donald A M, Bras W, Derbyshire G E, Mant G R and Ryan A J 1994 J. Polym. Sci. B 321579

[29] Ryan A J, Hamley I W, Bras W and Bates F S 1995 Macromolecules 283860

[30] Cernik R J 2016 J. Non-Cryst. Solids 4512

[31] Hatton P D, Thompson P and Glazer A M 1984 Acta Crystallogr. A $40 \mathrm{C} 395$

[32] Cernik R J et al 1997 J. Synchrotron Radiat. 4279

[33] Greaves G N, Fontaine A, Lagarde P, Raoux D and Gurman S J 1981 Nature 293611

[34] Greaves G N and Ngai K L 1995 Phys. Rev. B 526358

[35] Vessal B, Greaves G N, Marten P T, Chadwick A V, Mole R and Houde-Walter S 1992 Nature 356504

[36] Greaves G N, Meneau F, Majerus O, Jones D G and Taylor J 2005 Science 3081229

[37] Greaves G N, Meneau F, Sapelkin A, Colyer L M, Gwynn I A, Wade S and Sankar G 2003 Nat. Mater. 26222

[38] Greaves G N, Greer A L, Lakes R S and Rouxel T 2011 Nat. Mater. 10823 